\title{
Synthesis and characterization of a Nitrogenase-cofactor biomimetic based on molybdenum complexes with a polydentate- $\mathrm{N}_{5}$ ligand.
}

Steven Jiménez-Guailla ${ }^{1}$ Michelle Chicaiza-Lemus ${ }^{1}$ and Juan Pablo Saucedo-Vázquez ${ }^{1^{*}}$.

DOl. 10.21931/RB/2019.04.03.6

Abstract: Nitrogen fixation is an outstanding process in which atmospheric molecular nitrogen is reduced to ammonia, which is easier to assimilate by the plants. Due to the challenge to understand the nitrogen fixation process in vivo conditions, biomimetic compounds have been synthesized to perform the reduction of nitrogen in softest environments than in the Haber process. Thus, the purpose of this work is the synthesis and characterization of new molybdenum complexes with polydentate nitrogenated ligands and the evaluation of those complexes as possible dinitrogen reductants.

Key words: Nitrogenase, nitrogen fixation, biomimetic, molybdenum complex.

\section{Introduction}

Nitrogen fixation is a fundamental process to obtain ammonia and sustain life. There are at least three forms of nitrogen fixation in the earth: atmospheric, bacterial, and industrial production. The low concentration of ammonia is located in the troposphere, and most of it occurs in the agricultural process. By Keywords, nitrogen is fixed in the troposphere by photochemical reactions ${ }^{1}$ of dinitrogen in the presence of lightning; however, nitrogen oxides $\mathrm{NO}_{\mathrm{x}}$ produced in such reactions are less assimilable than ammonia or ammonium and do not contribute significantly to the nitrogen assimilation by the plants.

Haber Fritz proposed a production method of ammonia more than 100 years ago, then taken by Carl Bosch and converted into an industrial process ${ }^{2}$. In such a process, hydrogen required for the reduction of $\mathrm{N}_{2}$ is synthesized by a redox reaction between $\mathrm{CO}$ and $\mathrm{H}_{2} \mathrm{O}$, nitrogen is taken from air through distillation towers, then, both gases are directed to a chemical reactor and treated with an iron catalyst at high pressure $\left(\sim 150\right.$ bar) and high temperatures $\left(500-600^{\circ} \mathrm{C}\right)$ in order to obtain $\mathrm{NH}_{3}$ (equation 1). Haber-Bosch process is expensive and pollutant, however, about $40 \%$ of the earth population depends on the production of fertilizers coming from this process ${ }^{3}$.

$$
3 \mathrm{H}_{2(\mathrm{~g})}+\mathrm{N}_{2(\mathrm{~g})} \rightarrow 2 \mathrm{NH}_{3(\mathrm{~g})}
$$

In biological nitrogen fixation, Nitrogenase corresponds to a complex enzyme responsible of the fixation of atmospheric dinitrogen to a reduced form of nitrogen (i.e., amino, amido, imido, azido, nitrite or ammonia). In biology, only a specific group of microorganisms contains such an enzyme to make this a successful process. The first structural description of a nitrogenase enzyme corresponds to that of Azobacter vinelandii ${ }^{4}$.

The structure founded for its active site corresponds to a molybdenum (III) complex with an octahedral geometry on Mo with three sulfurs of the Fe-S cluster, two oxygen from the bidentate homocitrate and the imidazole group of a histidine (Figure 1$)^{5}$.

To contribute to a full understanding of the nitrogen fixation mechanism in vivo, synthesis of new functional biomimetic compounds suitable to reduce dinitrogen in softer conditions than the Haber-Bosch method have been reported. The synthesis of such nitrogenase cofactor biomimetics began with the synthesis of molybdenum-dinitrogen complexes, which were further functionalized to produce amides, hydrazide, and imido compounds because these compounds could be transformed to ammonia easily. In the first synthetic biomimetic complex, the oxidation state of molybdenum was zero, but, further investigations have improved the synthesis of new ligands, which tune the oxidation state of molybdenum ( $\mathrm{Mo}^{\prime \prime \prime}, \mathrm{Mo}^{\mathrm{v}}$, and $\mathrm{Mo}^{\mathrm{VI}}$ ) to increase their reactivity ${ }^{6}$. Besides, the nitrogenase mechanism according to the model of Thorneley and Lowe suggests that monoatomic nitrogen in the active center of the enzyme is reduced to form a nitride $\left(\mathrm{N}^{3-}\right)$ before the release of ammonia ${ }^{7}$. However, later ESEEM studies complemented the crystallographic results showed the presence of an interstitial carbon instead of a nitrogen atom ${ }^{8}$. Later is a clear example of the complexity of the mechanism of reduction of $\mathrm{N}_{2}$.

As an effort to contribute to the unraveling reaction mechanism of nitrogen fixation, we will propose the synthesis and characterization of molybdenum (III) complexes with ligands oxygen and nitrogen electron donors.

\section{Materials and methods}

All the reactants were of an analytical grade of purity and used without further purification. However, 2-pirydinecarboxylaldehyde and diethylenetriamine which were distilled before the reactions. UV-Vis spectra were obtained in a Perkin Elmer Lambda 1050 spectrophotometer; cyclic voltammograms were performed in a Metrhom Autolab PGSTAT302N potentiostat and NMR was obtained in a Varian $400 \mathrm{MHz}$ NMR Unity-Inova spectrometer.

\section{Synthesis of tris (acetylacetonato) molybdenum (III)}

The synthesis of tris (acetylacetonato) molybdenum (III) (Figure 3a) was performed according to the procedure reported previously ${ }^{9}$ but with slight changes and implementing two types of synthesis by changing the presence of inert $(\mathrm{He})$ atmosphere by air atmosphere. In a general procedure, $100 \mathrm{mg}$ of hexacarbonyl molybdenum (0) were dissolved in $5 \mathrm{ml}$ of acetylacetone. This mixture was stirred and refluxed for 2 hours, after that, the reaction was kept in a warm bath at $100{ }^{\circ} \mathrm{C}$ for 1 hour more, and then let it cooled at RT. Later, the solvent was removed and finally the solid was sublimated at around 
a

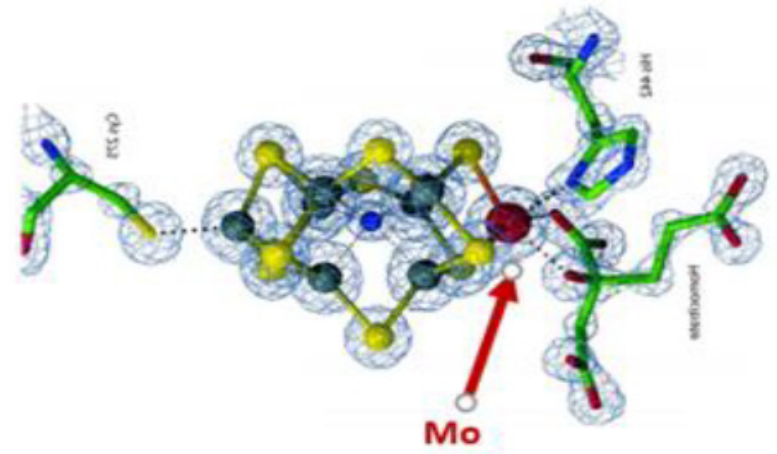

b

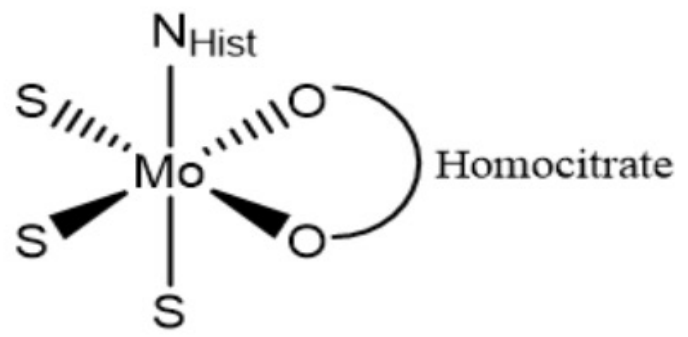

Figure 1. a) FeMo cofactor representation of A. vinelandii. Taken from Ref. 7. b) Octahedral geometry of molybdenum in the cofactor.

$150^{\circ} \mathrm{C}$ until the remnants of hexacarbonyl molybdenum do not sublimate anymore. The later procedure was performed under the exclusion of air by helium atmosphere and air without inert atmosphere.

\section{Synthesis of the ligand}

The synthesis of penta-amine ligand 1,9-bis(2'-pyrid$\mathrm{yl}$-2,5,8-triazonane was carried out according to the procedure previously reported ${ }^{10,11}$. In a round flask $25 \mathrm{~mL}$ of anhydrous ethanol, $2 \mathrm{~mL}(0.021 \mathrm{~mol})$ of 2-pyridinecarboxaldehyde and $1.13 \mathrm{~mL}(0.0105 \mathrm{~mol})$ of diethylenetriamine were placed together and the reaction mixture was heated to $55{ }^{\circ} \mathrm{C}$ with constant stirring. The reaction was followed by thin layer chromatography tests and using methanol: chloroform: hexane 1: 5: 3 mixture as an eluent to verify the disappearance of the aldehyde. Then, a catalytic $(\mathrm{Pd} / \mathrm{C})$ hydrogenation of the imine obtained in such synthesis was performed (Figure 2). The reduced polyamine pentadentate ligand was used without the formation of the hydrochloride as is described in $(10,11)$.

\section{Synthesis of the complex}

In a round flask, $25 \mathrm{~mL}$ of anhydrous ethanol, $2,5 \mathrm{~mL}$ of a $0,42 \mathrm{M}$ of the ligand and $414 \mathrm{mg}(1,05 \mathrm{mmol})$ were placed and stirred at $60{ }^{\circ} \mathrm{C}$ during 10 hours. After this time, a yellow-brown solid was obtained.

\section{Results and Discussion}

Two procedures were performed for the synthesis of tris (acetylacetonato)molybdenum(III), yields for both procedures (65\% He, 25\% air) and purity of the final product showed that helium atmosphere provides better results probably because inert sphere prevents the formation of oxo-molybdenum species.

Obtained product from the reaction under inert atmosphere was a dark purple solid (Figure $3 b$ ) with the physical characteristics of the previously reported for such compound, a melting point of $225-226{ }^{\circ} \mathrm{C}$ compared with those obtained in the literature ${ }^{9}$ indicates the success in the synthesis of the desired molybdenum complex.
From the reaction of 2-pirydinecarboxylaldehyde and diethylenetriamine we obtained the condensation product (imine) and the corresponding reduced amine via catalytic hydrogenation with $81 \%$ of yield. The obtained compound was characterized using NMR- $\mathrm{H}^{1}$ and assigned unambiguously to the pentadentate ligand (Figure 4).

The yellow-brown product obtained from the reaction between tris (acetylacetonate)molybdenum(III) and the pentadentate ligand 1,9-bis(2'-pyridyl)-2,5,8-triazonane presents a UV-Vis electronic spectra with three maximum in the UV region, two of them at high energy $(206,260 \mathrm{~nm})$ with large molar extinction coefficients $\left(7,760\right.$ and $\left.5,560 \mathrm{M}^{-1} \mathrm{~cm}^{-1}\right)$ that corresponds to charge transfer electronic transitions. The other transition is located at $309 \mathrm{~nm}$ and has a lower extinction coefficient $\left(890 \mathrm{M}^{-1} \mathrm{~cm}^{-1}\right)$ that could be assigned to a $\mathrm{d}-\mathrm{d}$ transition. In the case of our product, we expect a hexacoordinated octahedral complex, in which, five of the coordination positions are occupied by the pentadentate ligand and a labile solvent molecule in the sixth position. Thus, for an octahedral $d^{3}$ High Spin species, we expect three electronic transitions following the Tanabe-Sugano diagram ${ }^{12}$, however, as in the case of the $\mathrm{d}^{3}$ first row transition metals, the third transition ${ }^{4} T_{1 g}(P) \leftarrow{ }^{4} A_{2 g}$ for Mo (III) is expected to be at high energy and then obscured by the charge-transfer transitions. By the other hand, the literature is reported that the second and the third electronic transitions for Mo (III) HS are located in the UV region. For example, in the case of the $\left[\mathrm{Mo}\left(\mathrm{H}_{2} \mathrm{O}\right)_{6}\right]^{3+}$ such transitions are located at $310 \mathrm{~nm}$ for the second one ${ }^{4} \mathrm{~T}_{1 \mathrm{~g}}(\mathrm{~F}) \leftarrow{ }^{4} \mathrm{~A}_{2 \mathrm{~g}}$ and $380 \mathrm{~nm}$ for the first one ${ }^{4} \mathrm{~T}_{2 g} \leftarrow{ }^{4} \mathrm{~A}_{2 g}{ }^{13}$. In our case, we can assign the signal at $309 \mathrm{~nm}$ as the first electronic transition for the $d^{3}$ species; however, the second transition is most probably obscured by the charge transfer located at $260 \mathrm{~nm}$ (Figure 5a).

From cyclic voltammetry (Figure $5 b$ ), we observed a reversible process and determined a midpoint $\mathrm{E}_{m}=0,07 \mathrm{~V}(\mathrm{Fc})$ $\mathrm{FC}^{+}$) for our complex, such redox potential is in the same order that other for octahedral Mo (III) complexes, for example Mo$\mathrm{Cl}_{3}$ (pyridine) ${ }_{3}$ shows an $\mathrm{E}^{\circ}=0,49$ VSCE $[\mathrm{Mo}(\mathrm{III}) / \mathrm{Mo}(\mathrm{IV})]^{14}$.<smiles>O=Cc1ccccn1</smiles><smiles>NCCNCCN</smiles>

1) $\underset{\text { ethanol }}{\mathrm{pH}=4,5}$<smiles>NCc1ccccn1</smiles><smiles>CCCNCCN</smiles><smiles>NCc1ccccn1</smiles>

Figure 2. The reaction of Schiff base formation. 
a

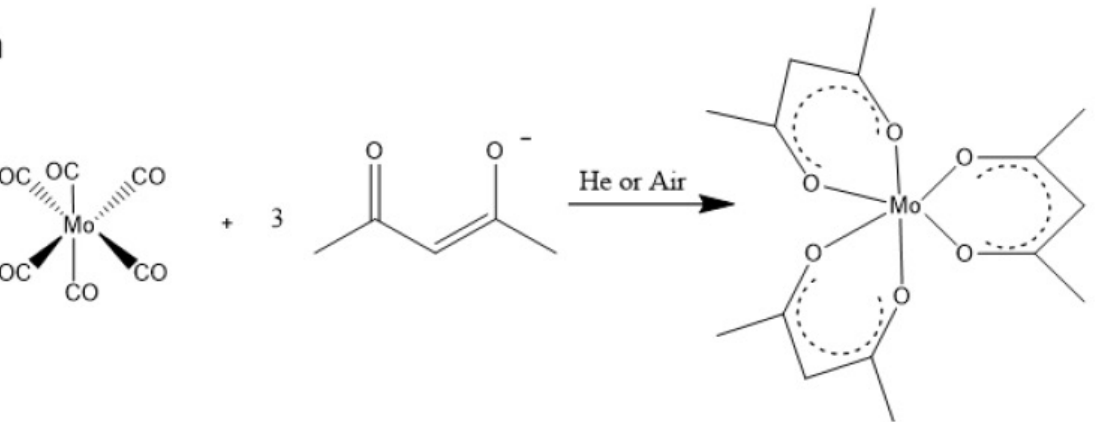

b

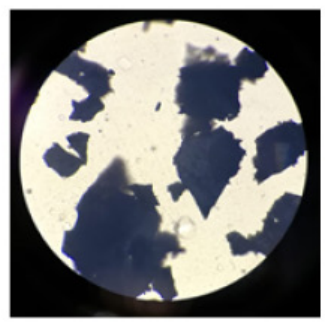

Figure 3. a) Synthesis reaction of tris (acetylacetonato) molybdenum (III) and b) Dark purple crystals obtained.

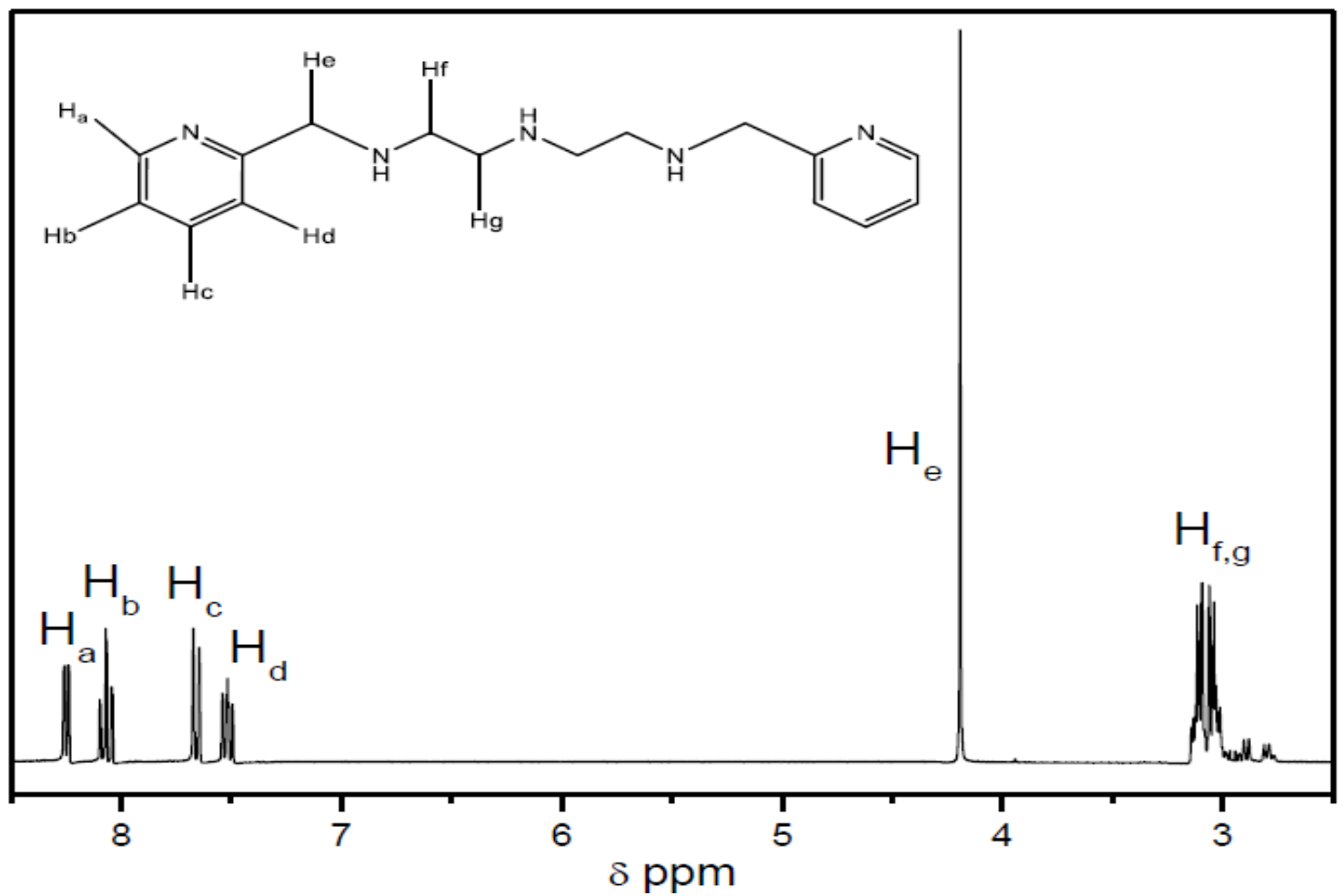

Figure 4. $400 \mathrm{MHz}^{1} \mathrm{H}$ NMR spectra of the pentadentate ligand in $\mathrm{D}_{2} \mathrm{O}$.
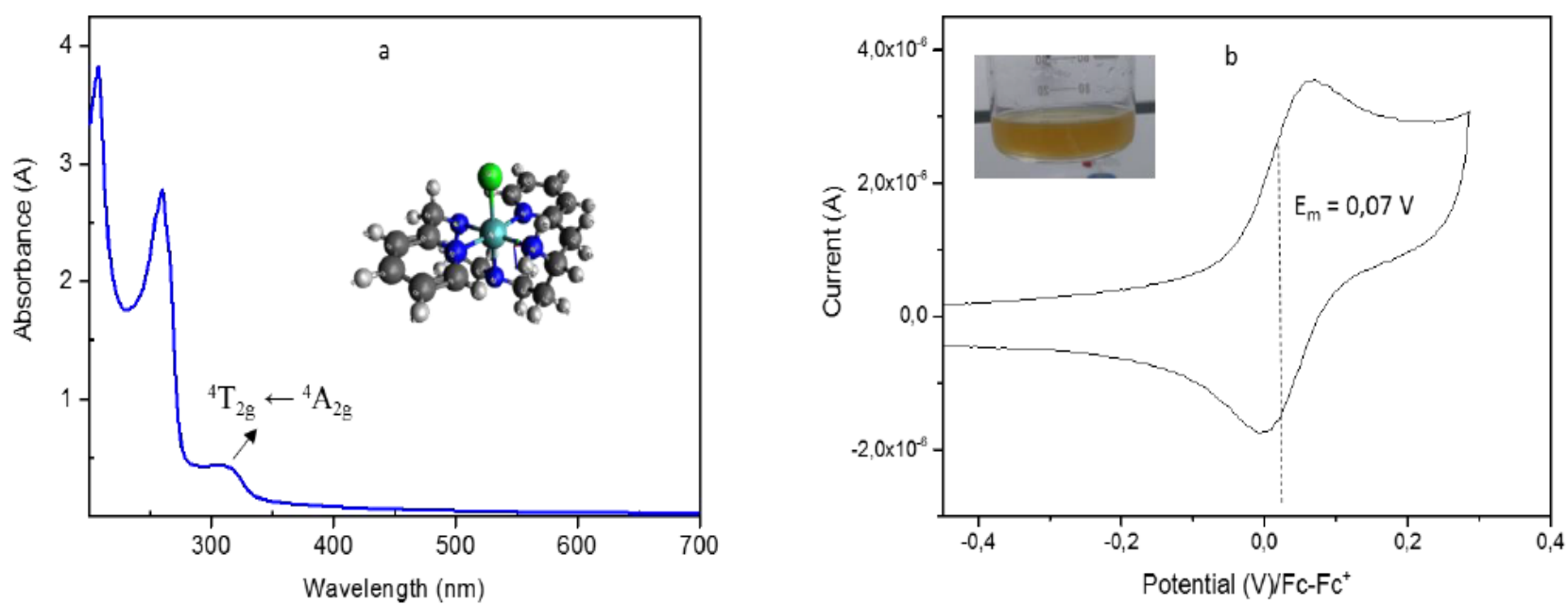

Figure 5. a) UV-vis spectrum and b) voltammogram of the molybdenum-polydentate complex in EtOH, $50 \mathrm{mV} / \mathrm{s}$. 


\section{Conclusions}

We performed the synthesis and partial characterization of a molybdenum complex coordinated with a pentadentate ligand. UV-Vis and electrochemical studies helped us to determine the oxidation state of Mo as 3+. The strategy of the synthesis was to have a complex with molybdenum in an octahedral environment with a pentadentate ligand and one labile position occupied by a solvent molecule. Such a labile position is expected to be a good site for the coordination of dinitrogen to induce the redox chemistry (nitrogen fix) between molybdenum and $\mathrm{N}_{2}$. Further characterization of the molybdenum complex is required to perform the next step of the biomimetic system. The reactivity of the synthesized compound with $\mathrm{N}_{2}$ is in the process of evaluation.

\section{Acknowledgements}

JPSV acknowledges the Yachay-Tech internal grant number 22; SJG and MCL acknowledge for the fellowship to INH.

\section{Bibliographic references}

1. Warneck P. Nitrogen Compounds in the Troposphere. In: Chemistry of the Natural Atmosphere. San Diego, CA: Academic; 1988. p. 422-83.

2. Leigh G.J. Haber-Bosch and Other Industrial Processes. In: Catalysts for Nitrogen Fixation Nitrogen Fixation: Origins, Applications, and Research Progress. Smith B.E., Richards R.L., Newton W.E., editors. Dordrecht: Springer; 2011.

3. Erisman J.W., Sutton M.A., Galloway J, Klimont Z, Winiwarter W. How a century of ammonia synthesis changed the world. Nature Geoscience. 2008;1(10):636-9

4. Kim J, Rees D. Structural models for the metal centers in the nitrogenase molybdenum-iron protein. Science. 1992. Sep18; 257(5077):1677-82.

5. Bjornsson R, Delgado-Jaime MU, Lima FA, Sippel D, Schlesier J, Weyhermüller T, et al. Molybdenum L-Edge XAS Spectra of MoFe Nitrogenase. Zeitschrift für anorganische und allgemeine Chemie. 2014; 641(1):65-71

6. Eizawa A, Nishibayashi Y. Catalytic Nitrogen Fixation Using Molybdenum-Dinitrogen Complexes as Catalysts. In: Nitrogen Fixation Topics in Organometallic Chemistry. Nishibayashi Y., editors. Springer, Cham; p. 153-9

7. Einsle O. Nitrogenase MoFe-Protein at 1.16 A Resolution: A Central Ligand in the FeMo-Cofactor. Science. 2002Sep6; 297(5587):1696-700.

8. Spatzal T, Aksoyoglu M, Zhang L, Andrade S, Schleicher E, Weber $\mathrm{S}$, Rees D, Einsle O. Evidence for Interstitial Carbon in Nitrogenase FeMo Cofactor. Science. 2011:334:940

9. Larson ML, Moore FW. Synthesis and Properties of Molybdenum(III) Acetylacetonate. Inorg Chem. 1962;1(4):856-9.

10. Raleigh C. J.; Martell A. E. Inorg. Chem. 1985; 24:142-148.

11. Saucedo-Vázquez J.P., Kroneck P.M.H., Sosa-Torres M.E. The role of molecular oxygen in the iron(III)-promoted oxidative dehydrogenation of amines. Dalton Transactions. 2015;44(12):5510-9

12. Huheey J.E., Keiter E.A., Keiter R.L. Appendix G: Tanabe-Sugano Diagrams. In: Inorganic chemistry: principles of structure and reactivity. 4th ed. New York, USA: Harper Collins College Publishers; 1993. p. A38-A39.

13. Ardon M, Pernick A. J. Molybdenum aquo ions in solution. Less Common Metals. 1977:54(1):233-241

14. Millar M. J. Am. Chem. Soc. Stable Monomeric Complexes of Molybdenum(III) and Tungsten(III). 1982:104:288-9 